\title{
Desenvolvimento de Massa de Pizza Enriquecida com Hibisco
}

\author{
Development of Pizza Pasta Enriched with Hibiscus
}

\begin{abstract}
Nara Vanessa dos Anjos Barros*a; Joana Carvalho Serraa ${ }^{\mathrm{a}}$ Rosielle Alves de Mouraa ; Paulo Víctor de Lima Sousa ${ }^{\mathrm{b}}$; Regina Márcia Soares Cavalcante
\end{abstract}

${ }^{a}$ Universidade Federal do Piauí. PI, Brasil.

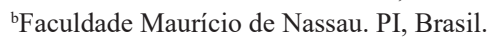

*E-mail: nara.vanessa@hotmail.com

\begin{abstract}
Resumo
Atualmente, busca-se constantemente o desenvolvimento de novos produtos para atender as necessidades dos consumidores, sendo a utilização do hibisco (Hibiscus sabidariffa L.) na produção alimentícia uma forma simples e econômica de agregar sabor aos produtos e beneficiar a saúde de quem os consome. O presente trabalho teve como objetivo desenvolver uma massa de pizza enriquecida com farinha de folhas de hibisco (FFH). Adicionou-se diferentes concentrações da FFH às massas de pizza, as quais foram submetidas às análises sensoriais e físicoquímicas. Não houve diferença estatística significativa entre a formulação I (massa de pizza enriquecida com 2\% de FFH) e a formulação II (massa de pizza enriquecida com $4 \%$ de $\mathrm{FFH}$ ) em relação à aceitação global. Para as análises físico-químicas, as formulações obtiveram teores

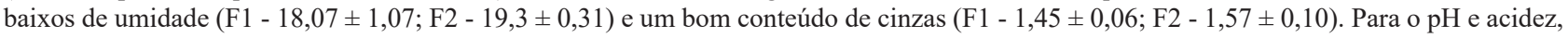
os resultados obtidos estão de acordo com o preconizado pela legislação vigente, com resultados que variaram de 5,0 a 6,0 para o pH, e de 1,7 a 2,8, para a acidez total titulável. Constatou-se que ambas amostras obtiveram boa aceitação por parte dos provadores, assim como uma intenção de compra satisfatória. Em relação às análises físico-químicas, verificou-se que os produtos desenvolvidos obtiveram características semelhantes a outras massas enriquecidas, estando de acordo com o preconizado nas legislações para este produto.
\end{abstract}

Palavras-chave: Desenvolvimento de Produtos. Hibiscus sabidariffa L. Produto de Panificação.

\begin{abstract}
Currently, there is a constant search for the development of new products to meet the consumer's needs, and the use of hibiscus (Hibiscus sabidariffa L.) in food production is a simple and economical way to add flavor to products and benefit the health of those who consume them. The present work had as objective to develop pizza dough enriched with hibiscus leaf flour (HLF). Different concentrations of HLF were added to the pizza masses, which were submitted to the sensorial and physicochemical analyzes. There was no statistically significant difference between formulation I (2\% HLF enriched pizza mass) and formulation II (4\% HLF enriched pizza mass) in relation to the overall acceptance. For the physicochemical analysis, the formulations obtained low levels of humidity (F1 - 18.07 $\pm 1.07 ;$ F2 - 19.3 \pm 0.31$)$ and a good ash content (F1 - $1.45 \pm 0$, 06; F2 - $1.57 \pm 0.10$ ). For $\mathrm{pH}$ and acidity, the results obtained are in accordance with the recommendations of the current legislation, with results ranging from 5.0 to 6.0 for $\mathrm{pH}$, and from 1.7 to 2.8 , for total titratable acidity. It was found that both samples obtained good acceptance by the tasters, as well as a satisfactory purchase intention. Regarding the physical-chemical analysis, it was found that the products developed obtained characteristics similar to other enriched masses, being in accordance with the recommendations in the legislation for this product.
\end{abstract}

Keywords: Product Development. Hibiscus Sabidariffa L. Bakery Product.

\section{Introdução}

A procura por alimentos saudáveis tem se tornado uma opção em destaque para uma parcela significativa da população, tendo em vista que a alimentação e nutrição constituem requisitos básicos para a promoção da saúde, sendo indispensáveis para o crescimento e desenvolvimento humano com qualidade de vida e cidadania (BRASIL, 2012).

A globalização atrelada ao aumento das exigências por parte dos consumidores tem aumentado significativamente o desenvolvimento e o lançamento de novos produtos na indústria alimentícia (ABREU, 2012). Neste contexto, CidOrtega e Guerrero-Beltrán (2015) destacaram os produtos alimentícios desenvolvidos a partir do hibisco (Hibiscus sabdariffa L.), uma vez que estes são considerados alimentos funcionais, devido à sua contribuição significativa de compostos bioativos em sua composição, como o polifenóis, flavonoides e antocianinas, que podem fornecer benefícios à saúde dos consumidores.

Nas folhas de hibisco está presente alguns flavonoides, os quais têm efeito cardioprotetor e vasodilatador. Tais compostos ajudam a aumentar o HDL (High Density Lipoproteins) e diminuir o LDL (Low Density Lipoproteins), os triglicerídeos e a pressão arterial (EMBRAPA, 2011). Ademais, eles também auxiliam na prevenção contra contaminação bacteriana, podendo ser utilizado na produção de alimentos para aumentar a vida de prateleira (MACIEL et al., 2012).

$\mathrm{O}$ hibisco vem sendo utilizado em uma grande variedade de pratos em alguns países como China, Índia, Malásia, África, Sudão, Austrália e México. Geralmente, os cálices e as flores do hibisco são os mais empregados na culinária para a produção de recheios doces, xaropes para confecção 
de geleias e vinhos, já as folhas são menos utilizadas e em alguns países, como Índia, são utilizadas na cocção de peixes e frangos para agregar sabor ou, na maioria das vezes, são desperdiçadas (ISLAM, 2019; ISLAM et al., 2016). No entanto, verifica-se que no Brasil, as folhas são utilizadas como ingrediente principal da preparação conhecida como arroz-de-cuxá, prato típico da cozinha maranhense, podendo ainda serem encontradas em preparações como sopas, molhos e saladas (FRANK et al., 2012; RIOS; PASTORE, 2011; VIZZOTTO; PEREIRA, 2010).

Dentre os produtos de panificações mais difundidos do mundo, tem-se a pizza, na qual foi introduzida no Brasil pela cultura italiana no final do século XX, sendo considerada um alimento de baixo custo, de preparo relativamente fácil e que possui diversos sabores disponíveis no mercado (CAMPELO et al., 2017; SOUSA et al., 2016).

Apesar da sua popularidade, as massas de pizza apresentam baixos teores de nutrientes e de compostos bioativos, devido a utilização de farinha de trigo refinada na sua preparação. Com isso, a utilização de ingredientes com propriedades funcionais, como as folhas do hibisco, torna-se uma alternativa para produção de alimentos mais saudáveis. Deste modo, o presente trabalho teve como objetivo desenvolver uma massa de pizza enriquecida com a farinha da folha de hibisco, analisando a aceitação sensorial e suas propriedades físico-químicas.

\section{Material e Métodos}

\subsection{Matérias-primas}

As folhas de hibisco utilizadas para elaboração das massas de pizzas foram coletadas no povoado Sitiozinho, no município de Dom Expedito Lopes, PI. As matérias-primas como: farinha de trigo, óleo vegetal de soja, fermento biológico, sal, açúcar e margarina (para untar a forma) utilizadas na preparação da massa foram armazenadas a temperatura ambiente $\left(22^{\circ} \mathrm{C}\right)$, ao passo que o queijo prato, peito de frango, tomate (Solanum lycopersicum), cebola (Allium cepa), coentro (Coriandrum sativum L.) pimenta de cheiro (Capsicum annuum), pimentão (Capsicum annuum Group), sal, corante, pimenta do reino (Piper nigrum), alho (Allium sativum), orégano (Origanum vulgare) e alecrim (Salvia rosmarinus), os quais foram empregados na preparação do molho caseiro, foram conservadas sob temperaturas de refrigeração $\left(8^{\circ} \mathrm{C}\right)$, no Laboratório de Tecnologia de Alimentos (LTA) do Campus Senador Helvídio Nunes de Barros da Universidade Federal do Piauí (CSHNB/UFPI), até o momento das análises, respeitando-se as especificidades de cada matéria-prima. Todas as matérias-primas foram adquiridos no mercado do município de Picos, PI.

\subsection{Elaboração do produto}

\subsubsection{Processo de secagem das folhas de hibisco}

As folhas foram lavadas em água destilada e imersas em solução de hipoclorito de sódio durante 15 min para sanitização e, posteriormente, enxaguadas com água em abundância para remoção da solução e limpeza. Logo em seguida, foram submetidas ao processo de secagem em desidratador PraticDryer ${ }^{\circledR}$ de leito fixo ascendente na temperatura de 60 ${ }^{\circ} \mathrm{C}$ e velocidade do ar de $1,00 \mathrm{~m} \mathrm{~s}^{-1}$, onde permaneceram por aproximadamente 7 horas.

\subsubsection{Obtenção da farinha da folha de hibisco (FFH)}

O resíduo da folha de hibisco desidratado foi triturado no liquidificador doméstico marca Philips Walita por um minuto. Em seguida, peneirou-se a farinha em peneira granulométrica (0,5 mesh), a fim de obter uma farinha de granulometria uniforme. Após esta etapa, a FFH foi dividida em amostras de $10 \mathrm{~g}$, as quais foram posteriormente embaladas em saco plástico de polietileno sem vácuo envolto com papel alumínio e armazenado em poliestireno expandido a temperatura ambiente, longe do alcance da luz.

\subsubsection{Processamento das massas de pizzas}

Para elaboração das massas, adicionou-se em um recipiente grande (5 litros), o açúcar, o fermento, o sal, o óleo vegetal de soja, a água morna $\left(37^{\circ} \mathrm{C}\right)$ e água fria $\left(15^{\circ} \mathrm{C}\right)$, e misturou-se até a completa dissolução. Em seguida, adicionouse a FFH e a farinha de trigo aos poucos, as quais foram sovados, manualmente, até total homogeneização, durante aproximadamente cinco minutos. Deixou-se descansar essa massa por uma hora, para que a mesma fermentasse e crescesse. Em seguida, a mesma foi espalhada em uma forma untada com margarina, recheada com molho e queijo dividida em pequenas porções individuais (40 g) com o auxílio de um cortador. Foram então colocadas no forno para assar, a temperatura de $220^{\circ} \mathrm{C}$ por aproximadamente $30 \mathrm{~min}$. (ou até observar que a parte inferior da massa estava dourada). As formulações desenvolvidas estão descritas no Quadro 1.

Quadro 1 - Formulações de massas de pizza com farinha da folha de Hibiscus sabdariffa L. (FFH)

\begin{tabular}{|l|c|c|c|}
\hline Matérias-primas (\%) & & Formulações & \\
\hline & C & FI & FII \\
\hline Farinha de trigo & 59,4 & 57,3 & 55,1 \\
\hline FFH & 0,00 & 2,10 & 4,30 \\
\hline Sal & 0,50 & 0,50 & 0,50 \\
\hline Açúcar & 2,00 & 2,00 & 2,00 \\
\hline Óleo vegetal de soja & 1,30 & 1,30 & 1,30 \\
\hline Fermento biológico & 1,30 & 1,30 & 1,30 \\
\hline Agua morna & 18,2 & 18,2 & 18,2 \\
\hline Agua fria & 18,2 & 18,2 & 18,2 \\
\hline
\end{tabular}

Legenda: C - controle; FI - $2 \%$ da FFH na massa; FII - 4\% da FFH na massa.

Fonte: Dados da pesquisa.

\subsection{Análise sensorial dos produtos elaborados}

A análise sensorial foi realizada por um painel composto por 100 provadores não treinados, de ambos os sexos, com idade entre 19 e 45 anos, consumidores potenciais do produto, recrutados entre acadêmicos, funcionários e professores da 
UFPI, após a assinatura do Termo de Consentimento Livre e Esclarecido - TCLE. As amostras foram oferecidas em pratos descartáveis, codificados com números de três dígitos aleatoriamente, acompanhadas de um garfo e copo com água potável filtrada para fazer o branco entre as amostras.

Os testes utilizados para verificar a aceitação e preferência dos produtos foram a Escala Hedônica estruturada de nove pontos e o teste discriminativo de Comparação Pareada. No teste de Escala Hedônica, os provadores julgaram as amostras e atribuíram notas que variavam de 1 a 9 ao produto, correspondendo desde desgostei muitíssimo (nota 1) a gostei muitíssimo (nota 9). No teste de Comparação Pareada, as amostras foram oferecidas em pares simultaneamente aos provadores, e estes escolheram a de sua preferência, conforme a metodologia descrita por Dutcosky (2013).

Avaliou-se, também a Intenção de Compra dos produtos por meio da aplicação de uma escala de 5 pontos variando de "certamente não compraria" a "certamente compraria". Calculou-se ainda, o Índice de Aceitação (IA) do produto, pela fórmula, $\mathrm{IA}=\mathrm{A} / \mathrm{Bx} 100$, onde $\mathrm{A}=$ Nota média obtida para o produto e $\mathrm{B}=$ Nota máxima dada ao produto. Para que um produto seja considerado bem aceito pelos provadores, o IA deve ser $\geq 80 \%$ (DUTCOSKY, 2013).

\subsection{Caracterização físico-química}

Para caracterização físico-química das massas de pizzas foram realizadas as análises de umidade, cinzas, potencial hidrogeniônico $(\mathrm{pH})$ e acidez total titulável, conforme a metodologia descrita pelo Instituto Adolfo Lutz (2008).

\subsubsection{Umidade}

A umidade foi determinada por secagem em estufa (marca Odontobrás) a $105^{\circ} \mathrm{C}$, até a amostra adquirir peso constante. Para a análise, foram pesadas $5 \mathrm{~g}$ de amostra em cápsulas de porcelana previamente taradas. As amostras foram aquecidas durante $3 \mathrm{~h}$, resfriadas em dessecador em temperatura ambiente e depois pesadas em balança analítica da marca Radwag com precisão de 0,0001g. Esta operação de aquecimento e resfriamento das cápsulas com as amostras foi repetida até obtenção de peso constante da amostra seca. Os resultados foram expressos em porcentagem na base úmida, segundo a seguinte fórmula: (IAL, 2008)

Umidade $(\%)=[$ amostra integral $(\mathrm{g})-\operatorname{amostra} \operatorname{seca}(\mathrm{g})]$ X 100 Amostra integral

\subsubsection{Cinzas}

As cinzas foram determinadas por incineração em forno mufla (marca Jung) a $550^{\circ} \mathrm{C}$ até peso constante. Foram pesadas aproximadamente $5 \mathrm{~g}$ das amostras em cadinhos previamente tarados, em seguida, carbonizados e levados ao forno mufla para incineração, até ficarem brancas. Após o resfriamento em dessecador, procederam-se as pesagens. Os resultados foram expressos em porcentual de cinzas, conforme segue: (IAL,
2008)

Teor de cinzas $=100 \times \mathrm{N} / \mathrm{P}$

em que: $\mathrm{N}=\mathrm{n}^{\circ}$ de gramas de cinzas e $\mathrm{P}=\mathrm{n}^{\circ}$ de gramas de amostra.

\subsection{3 pH}

Para obtenção do $\mathrm{pH}$, foram utilizados $10 \mathrm{~g}$ das amostras maceradas, em $100 \mathrm{~mL}$ de água destilada, agitando-se durante 30 minutos em agitador magnético da marca BiomiXer. Posteriormente, foi realizada a leitura do líquido sobrenadante em pHmetro da marca Quimis, previamente calibrado com solução tampão de pH 4,0 e 7,0 (IAL, 2008).

\subsubsection{Acidez total titulável}

A análise de acidez total titulável seguiu normas do Instituto Adolf Lutz (2008), onde $10 \mathrm{~g}$ das amostras foram adicionadas a $50 \mathrm{~mL}$ de água e três gotas do indicador fenolftaleína em erlenmeyer e titulado com $\mathrm{NaOH}(0,1 \mathrm{~N})$ em bureta de $25 \mathrm{~mL}$. Os resultados foram expressos em $\mathrm{g} 100 \mathrm{~g}^{-1}$ de ácido cítrico (IAL, 2008). Para o cálculo da acidez total, utilizou-se a fórmula abaixo:

Acidez total titulável $(\%)=\frac{\mathrm{V} * \mathrm{f} * 100 * \text { Fator do ácido }}{P}$

em que: $\mathrm{V}=\mathrm{n}^{\mathrm{o}}$ de $\mathrm{mL}$ da solução de hidróxido de sódio gasto na titulação; $\mathrm{f}=$ fator da solução de hidróxido de sódio; Fator do ácido = fator do ácido em predominância na amostra; $\mathrm{P}=\mathrm{n}^{\mathrm{o}}$ de $\mathrm{g}$ ou $\mathrm{mL}$ da amostra usado na titulação

\subsection{Análise estatística}

Os resultados das análises físico-químicas foram expressos como a média das três repetições e respectivo desvio-padrão (DP), por meio do Programa Excel. Para verificar a diferença nas notas de aceitação entre as formulações desenvolvidas, utilizou-se o programa estatístico Assistat versão 7.7., sendo submetidas ao teste t de Student com 5\% de probabilidade $(\mathrm{p} \leq 0,05)$ e intervalo de confiança (IC) de $95 \%$. Além disso, os demais resultados dos testes sensoriais (preferência, índice de aceitação e intenção de compra) foram expressos na forma de médias e porcentagens, e demonstrados nos quadros.

\subsection{Aspectos éticos}

O projeto foi submetido e aprovado em seus aspectos éticos e metodológicos pelo Comitê de Ética em Pesquisa da UFPI (parecer de $\mathrm{n}^{\mathrm{o}}$ 0376.0.045.000-16). Todos os participantes assinaram o Termo de Consentimento Livre Esclarecido (TCLE) antes da realização da análise sensorial, segundo as diretrizes da resolução n. ${ }^{\circ}$ 466, de 12 de dezembro de 2012 (BRASIL, 2012).

Foram inclusos participantes de ambos os sexos, que tinham idade entre 19 e 45 anos e possuírem algum elo de ligação com a Universidade Federal do Piauí, Campus Senador Helvídio Nunes de Barros. Os mesmos eram consumidores potenciais do produto desenvolvido, não possuíam alergia/ intolerância aos ingredientes utilizados e aceitaram participar 
da pesquisa voluntariamente.

\section{Resultados e Discussão}

\subsection{Análise Sensorial}

Com relação aos provadores, observou-se que 67\% eram do sexo feminino e $33 \%$ do sexo masculino, com uma média de idade de 26 anos. Assim, demonstram-se nos Quadros 2 e 3 os resultados da análise sensorial para o teste da escala hedônica e os obtidos em relação a aceitação global e índice de aceitação, respectivamente.

Quadro 2 - Porcentagem das notas obtidas no teste da escala hedônica para as formulações de massas de pizza enriquecida com farinha da folha de Hibiscus sabdariffa L. (FFH). Formulação I - massa de pizza enriquecida com $2 \%$ de FFH; Formulação II massa de pizza enriquecida com $4 \% \mathrm{FFH}$

\begin{tabular}{|l|c|c|}
\hline \multirow{2}{*}{\multicolumn{1}{|c|}{ Notas }} & \multicolumn{2}{c|}{ Escala Hedônica (\%) } \\
\cline { 2 - 3 } & $\begin{array}{c}\text { Formulação } \\
\text { I }\end{array}$ & $\begin{array}{c}\text { Formulação } \\
\text { II }\end{array}$ \\
\hline 1-Desgostei muitíssimo & 1 & 1 \\
\hline 2-Desgostei muito & 1 & 0 \\
\hline 3-Desgostei moderadamente & 2 & 1 \\
\hline 4-Desgostei ligeiramente & 1 & 3 \\
\hline 5-Nem gostei, nem desgostei & 7 & 6 \\
\hline 6-Gostei ligeiramente & 5 & 11 \\
\hline 7-Gostei moderadamente & 23 & 19 \\
\hline 8-Gostei muito & 32 & 30 \\
\hline 9-Gostei muitíssimo & 28 & 29 \\
\hline
\end{tabular}

Fonte: Dados da pesquisa.

A partir dos comentários advindos dos provadores, observou-se que uma parte preferiu a formulação I por ter um sabor mais próximo ao produto tradicional, enquanto outros optaram pela formulação II exatamente por ser mais concentrada e ter um sabor mais acentuado, o que segundo eles, tornava o produto diferente, mais saboroso. Alguns avaliadores comentaram ainda que gostaram de ambas formulações, o que justifica a atribuição de notas semelhantes.

Quadro 3 - Aceitação global e índice de aceitação das diferentes formulações de massas de pizza enriquecidas com farinha da folha de Hibiscus sabdariffa L. (FFH)

\begin{tabular}{|c|c|c|}
\hline Amostras & Aceitação Global & IA (\%) \\
\hline Formulação I & $7,47^{\mathrm{a}}$ & $83 \%$ \\
\hline Formulação II & $7,46^{\mathrm{a}}$ & $82,9 \%$ \\
\hline
\end{tabular}

Legenda: Letras iguais na mesma coluna não diferem entre si, ao nível de $5 \%$ de probabilidade (Teste t de Student). Formulação I - massa de pizza enriquecida com $2 \%$ de FFH; Formulação II - massa de pizza enriquecida com 4\% FFH; IA: índice de aceitabilidade.

Fonte: Dados da pesquisa.

No Quadro 3, observou-se que a média das notas para o teste da escala hedônica encontrou-se entre as notas "gostei moderadamente" e "gostei muitíssimo", o que demonstraram uma boa aceitação de ambas formulações, por parte dos consumidores, não havendo diferença estatística significativa entre as mesmas. Tal fato pode ser confirmado analisando-se o índice de aceitação (IA), que obteve como resultados $83 \%$ para formulação I (massa de pizza enriquecida com $2 \%$ de
FFH) e $82,9 \%$ para formulação II (massa de pizza enriquecida com $4 \%$ de FFH), indicando que ambas foram bem aceitas pelos provadores e provavelmente podem ser bem aceitas comercialmente, uma vez que este índice deve ser $\geq 80 \%$, segundo Dutcosky (2013).

Russo et al. (2012) ao analisarem massas de pizzas enriquecidas com diferentes concentrações de farinha de trigo integral e linhaça em relação a aparência, aroma e sabor, não observaram diferença estatística significativa para tais parâmetros. Este fato também foi verificado por Sousa et al. (2016) que elaboraram massa de pizza enriquecidas com farinha de aveia, na qual os atributos sensoriais de sabor e aceitação global não diferiram estatisticamente entre si para as diferentes concentrações de farinha de aveia, e por Campelo et al. (2017) que demonstraram que a adição de 5 a $20 \%$ da farinha de atum à massa de pizza não alterou significativamente os parâmetros de aroma, sabor e impressão geral.

Ao comparar o índice de aceitação dos produtos desenvolvidos com outras pesquisas, como Russo et al. (2012), obtiveram índices inferiores para formulações com 2,5\% e 5\% de farinha de linhaça, de $74,5 \%$ e $76,5 \%$, respectivamente. Deste modo, verificou-se que as massas de pizza enriquecida com farinha da folha de hibisco apresentaram índice de aceitação maior que as massas enriquecidas com outras farinhas, mostrando assim um maior potencial para serem consumidas.

Camacho Flinois, Dando e Padilla-Zakour (2019) que utilizaram o soro do leite do iogurte de tipo grego para a formulação de produtos de panificação, como a massa de pizza, demonstraram a importância da reciclagem de ingredientes da indústria de alimentos para a reintrodução de nutrientes nos produtos alimentares, em vez de descartá-los.

Abreu et al. (2019) analisaram os compostos bioativos no cálice de Hibiscus sabdariffa L. e verificaram os teores de compostos fenólicos totais e a atividade antioxidante, respectivamente, iguais a 429,84 $\pm 5,16$ (equivalentes de ácido gálico-EAG/100g) e 626,32 $\pm 8,03$ ( $\mu$ moltrolox/L). Formagio et al. (2015) analisaram diferentes partes da planta e observaram maior conteúdo de fenólicos e flavonoides em extratos do cálice (474.09 e $148.35 \mathrm{mg} \mathrm{g}^{-1}$, respectivamente), em relação aos extratos das folhas (389.98 e $104.52 \mathrm{mg} \mathrm{g}^{-1}$, respectivamente).

A partir disso, a substituição parcial da farinha de trigo refinado por outros ingredientes, como as folhas do hibisco, pode ser uma alternativa à utilização dessa farinha, pois, além de agregar nutrientes e compostos bioativos à massa da pizza quando comparada a pizza tradicional, contribui para a redução de desperdícios dos subprodutos da matéria-prima. Ademais, apesar de ser uma matéria-prima extensivamente estudada quanto suas propriedades nutritivas e funcionais, há uma escassez de estudos sobre sua aplicação em produtos alimentícios, sugerindo-se, assim, a aplicação das folhas de hibisco a outros produtos de panificação, tais como pães, bolos, esfihas, pasteis, entre outros. 
No Quadro 4, observou-se que as porcentagens de notas obtidas para a intenção de compra das duas formulações em estudo.

Quadro 4 - Intenção de compra das diferentes formulações de massas de pizza enriquecida com farinha da folha Hibiscus sabdariffa L. (FFH)

\begin{tabular}{|l|c|c|}
\hline \multirow{2}{*}{ Notas } & \multicolumn{2}{|c|}{ Intenção de Compra (\%) } \\
\cline { 2 - 3 } & $\begin{array}{c}\text { Formulação } \\
\text { I }\end{array}$ & $\begin{array}{c}\text { Formulação } \\
\text { II }\end{array}$ \\
\hline 1-Certamente não compraria & 2 & 2 \\
\hline 2-Provavelmente não compraria & 5 & 4 \\
\hline 3-Talvez compraria & 13 & 18 \\
\hline 4-Provavelmente compraria & 25 & 32 \\
\hline 5-Certamente compraria & 55 & 44 \\
\hline
\end{tabular}

Legenda: Formulação I - massa de pizza enriquecida com 2\% de FFH;

Formulação II - massa de pizza enriquecida com $4 \%$ FFH.

Fonte: Dados da pesquisa.

Verificou-se que ambas as formulações possuem potencial para serem inseridas no mercado de produtos de panificação, uma vez que há uma boa intenção de compra para as mesmas por parte dos consumidores avaliados. Observou-se que $80 \%$ dos provadores provavelmente ou certamente comprariam a formulação I, enquanto que $76 \%$ comprariam a formulação II.

Russo et al. (2012) obtiveram como intenção positiva (certamente compraria/provavelmente compraria) para aquisição da massa de pizza enriquecida com farinha de linhaça a $2,5 \%$ e $5,0 \%$, com um porcentual de $58,82 \%$ e $60,78 \%$, respectivamente. Sousa et al. (2016) também demonstraram resultados positivos em que $31 \%$ dos provadores afirmaram que certamente comprariam a formulação que teve a adição de $15 \%$ de farinha de aveia. Campelo et al. (2017) demonstraram que a adição de 5 a $20 \%$ da farinha de atum à massa de pizza não houve diferença significativa na intenção de compra entre as formulações, com notas próximas a pontuação 3 (talvez compraria).

Já Morais et al. (2014) verificaram para massa de pizza enriquecida com amêndoa de castanha de caju a $5 \%$ um percentual de $65 \%$, enquanto que as massas de pizza enriquecida a $2 \%$ e a $4 \%$ com farinha de hibisco obtiveram uma intenção de compra superior a estas.

Deste modo, verificou-se que o presente estudo obteve resultados positivos semelhantes ao de outros autores, os quais demonstraram boa viabilidade de comercialização, bem como a incorporação de outras matérias-primas na formulação de produtos, como a massa de pizza. Assim, seria uma alternativa viável que não levaria à mudanças nas características sensoriais do produto considerado padrão do mercado.

Em relação à preferência dos produtos, constatou-se que $55 \%$ preferiram a formulação I, enquanto $45 \%$ a formulação II. Por meio da tabela de distribuição $\chi 2$, não houve diferença estatística significativa entre as amostras a um nível de 5\% de probabilidade (DUTCOSKY, 2013), apesar de mais da metade dos provadores terem preferido a formulação I.

Isso ocorreu provavelmente porque a formulação I apresentou menor concentração da farinha de hibisco, e deste modo um sabor mais próximo ao do produto tradicional, o que está de acordo com o verificado no estudo de Silva e Araújo (2015), que utilizaram diferentes concentrações de farinha de feijão-caupi (Vigna unguiculata (L.) Walp.) para enriquecer massas de pizza, e observaram que os provadores preferiram a de menor concentração.

\subsection{Caracterização Físico-química}

Apresentam-se no Quadro 5, os teores médios dos resultados verificados nas análises físico-químicas das massas de pizza elaboradas.

Quadro 5 - Caracterização físico-química das formulações de massas de pizza enriquecida com farinha da folha de Hibiscus sabdariffa L. (FFH).

\begin{tabular}{|c|c|c|}
\hline $\begin{array}{c}\text { Composição } \\
\text { Físico-Química }\end{array}$ & Formulação I & Formulação II \\
\hline Umidade (\%) & $18,07 \pm 1,07$ & $19,3 \pm 0,31$ \\
\hline Cinzas (\%) & $1,45 \pm 0,06$ & $1,57 \pm 0,10$ \\
\hline Acidez (mg/100g) & $1,71 \pm 0,07$ & $2,80 \pm 0,04$ \\
\hline $\mathrm{pH}$ & $6,085 \pm 0,21$ & $5,79 \pm 0,50$ \\
\hline
\end{tabular}

Legenda: resultados expressos como média \pm desvio padrão; Formulação I - 2\% da FFH na massa; Formulação II - 4\% da FFH na massa.

Fonte: Dados da pesquisa

Observou-se que ambas amostras exibiram um teor de umidade relativamente baixo, sendo tal fato importante, por estar diretamente associada à vida de prateleira do produto, já que alimentos que apresentam menor umidade proporcionam um menor desenvolvimento de microorganismos e, consequentemente, uma vida de prateleira maior. Com relação às cinzas, percebeu-se que a formulação II apresentou maior teor que a formulação I, o que já era esperado, uma vez que naquela foi adicionado uma maior quantidade de FFH.

Ao analisar os teores de umidade em pizzas enriquecidas, observaram-se algumas discrepâncias entre os resultados obtidos em outros estudos, devido à diversidade de matériasprimas utilizadas para enriquecer as massas. Dentre estas, destacam-se os valores $24,4 \%$ e $14,67 \%$ verificados por Silva e Araújo (2015) e Russo et al. (2012), ao desenvolverem massas com farinha de feijão-caupi e farinha de trigo integral e linhaça, respectivamente.

Já outros autores obtiveram valores mais elevados de umidade, como Campelo et al. (2017) com teores na faixa de $27 \%$ a $30 \%$ em massa de pizza com farelo de atum, Camacho Flinois, Dando e Padilla-Zakour (2019) com valor aproximadamente de $32 \%$ em massa de pizza com soro do leite de iogurte do tipo grego e Abdel-Moemin (2016) com $29 \%$ de umidade em cupcakes elaborado com o cálice do hibisco.

Apesar do mencionado, os valores de cinzas encontramse semelhantes aos referidos estudos, em que Silva e Araújo (2015) e Russo et al. (2012) encontraram 2,2\% e 1,53\%, respectivamente. Entretanto, Campelo et al. (2017) e AbdelMoemin (2016) demonstraram valores elevados de cinzas na 
fixa de $2,5 \%$ a $4,2 \%$.

Para tanto, a RDC n. ${ }^{\circ} 93$ de 2000 estabelece um máximo de $2,5 \%$ de cinzas em massas alimentícias, demonstrando que os resultados do presente estudo estavam dentro do preconizado pela legislação (BRASIL, 2000).

Observou-se que, com relação à acidez total titulável, o produto estudado obteve valores $(\mathrm{F} 1=1,71$ e $\mathrm{F} 2=2,80)$ semelhantes aos obtidos por Pinho, Machado e Furlong (2001) em marcas comerciais de pizza, explanado por uma variação de 0,3 a 1,7. Estes valores encontram-se dentro do estabelecido por Brasil (2000), a qual indica 5\% no máximo. No entanto, Abdel-Moemin (2016) verificou um valor de 14 , sendo esse resultado superior ao verificado no produto da pesquisa. Quanto ao $\mathrm{pH}$, o valor verificado foi próximo aos resultados dos estudos supracitados, destacando valores para este parâmetro que variaram de 5,5 a 6,2, porém, AbdelMoemin (2016) obteve um valor elevado de $\mathrm{pH}$ de 7,5 nas amostras de cupcakes elaborado com o cálice do hibisco.

Tais valores estão relacionados à vida de prateleira do produto, sendo que um $\mathrm{pH}$ muito elevado contribui para o desenvolvimento de microorganismos contaminantes, e consequente deterioração do produto, implicando ainda em risco de vida para os consumidores. Ademais, segundo Quaglia (1991), os valores de $\mathrm{pH}$ e acidez obtidos em produtos de panificação podem estar relacionados às técnicas de preparação, tendo em vista que a ocorrência de $\mathrm{pH}$ e índice de acidez, ambos elevados ou diminuídos nesses produtos, podem indicar que a fermentação foi realizada a uma temperatura alta e durante um tempo superior ao necessário.

\section{Conclusão}

As massas de pizza enriquecida com farinha da folha de hibisco (Hibiscus sabdariffa L.) apresentaram, em ambas formulações, boa aceitação e viabilidade para a comercialização, sendo esse um aspecto positivo, visto que a massa é enriquecida com uma matéria-prima regional e rica em compostos bioativos, além de ser um produto alimentício que aproveita matérias-primas que na maioria das vezes são desperdiçadas. Com relação as características físico-químicas, estas estavam de acordo com o preconizado nas legislações para esse tipo de produto.

\section{Referências}

ABDEL-MOEMIN, A. R. Effect of Roselle calyces extract on the chemical and sensory properties offunctional cupcakes. Food Scie. Hum. Wellness, v.5, n.4, p.230-237, 2016. doi: 10.1016/j. fshw.2016.07.003

ABREU, A. A importância da inovação tecnológica na indústria de alimentos: um estudo de caso numa empresa de grande porte. In: ENCONTRO NACIONAL DE ENGENHARIA DE PRODUÇÃO. Bento Gonçalves, RS, Brasil 15 a 18 de outubro de 2012 .

ABREU, B. B. et al. Composição centesimal, compostos bioativos e atividade antioxidante em cálice de hibisco (Hibiscus sabdariffa L.). J. Int. Bioc., v.4, n.1, p.1-4, 2019. doi: 10.26694/ jibi.v4i1.7618
BRASIL. Agência Nacional de Vigilância Sanitária. Resolução $R D C n^{\circ}$ 93, de 31 de outubro de 2000: dispõe sobre o Regulamento Técnico para Fixação de Identidade e Qualidade de Massa Alimentícia. Disponível em: http://bvsms.saude.gov.br/ bvs/saudelegis/anvisa/2000/rdc0093_31_10_2000.html. Acesso em: 1 abr..2020.

BRASIL. Conselho Nacional de Saúde. Resolução RDC $n^{\circ}$ 466, de 12 de dezembro de 2012: aprova diretrizes e normas regulamentadoras de pesquisa envolvendo seres humanos. Diário Oficial da União, Brasília, 12 dez. 2012. Disponível em: <http:// conselho.saude.gov.br/resolucoes/2012/Reso466.pdf>. Acesso em: 23 jun. 2020.

BRASIL. Ministério da Saúde. Secretaria de Atenção à Saúde. Departamento de Atenção Básica. Política Nacional de Alimentação e Nutrição. Brasília: MS, 2012.

CAMACHO FLINOIS, J.; DANDO, R.; PADILLA-ZAKOUR, O. I. Yogurt acid whey utilization for production of baked goods: pancakes and pizza crust. Foods, v.8, n.12, 2019. doi: 10.3390/ foods 8120615

CAMPELO, D.A.V. et al. Addition of different tuna meal levels to pizza dough. Braz. J. Food Technol., v.20, e2016014, 2017. doi: 10.1590/1981-6723.1416

CID-ORTEGA, S.; GUERRERO-BELTRÁN, J.A. Roselle calyces (Hibiscus sabdariffa), an alternative to the food and beverages industries: a review. J. Food Sci Technol., v.52, n.11, p.6859-6869, 2015. doi: 10.1007/s13197-015-1800-9

DUTCOSKY, S. D. Análise sensorial de alimentos. Curitiba: Champagnat, 2013.

EMBRAPA. Clima temperado - Hibisco: do uso ornamental ao medicinal. 2011. Disponível em: $<$ http://www.embrapa.com.br $>$. Acesso em: 12 jan. 2020

FORMAGIO, A. S. N. et al. Compostos fenólicos de Hibiscus sabdariffa e influência de resíduos orgânicos em sua propriedade antitumoral e antioxidante. Braz. J. Biol., v.75, n.1, p.69-76, 2015. doi: 10.1590/1519-6984.07413.

FRANK, T. et al. Consumption of Hibiscus sabdariffa L. aqueous extract and its impact on systemic antioxidant potential in healthy subjects. J. Sci. Food Agric., v.92, n.10, p.2207-2218, 2012. doi: $10.1002 /$ jsfa. 5615

IAL. Instituto Adolfo Lutz. Métodos físico-químicos para análise de alimentos. São Paulo: ANVISA, 2008, 1020p.

ISLAM, M. Food and medicinal values of roselle (Hibiscus sabdariffa L. Linne Malvaceae) Plant Parts: A Review. Open J. Nutr. Food Sci., v. 1, n. 1003, p. 14-20, 2019.

ISLAM, A.K.M.A. et al. Roselle: a functional food with high nutritional and medicinal values. Fund. Appl. Agric., v. 1, n. 2, p.44-49, 2016.

MACIEL, M. J. et al. Avaliação do extrato alcoólico de Hibisco (Hibiscus sabdariffa L.) como fator de proteção antibacteriana e antioxidante. Rev Inst Adolfo Lutz, v. 71, n. 3, p. 462-470, 2012.

MORAIS, B.A. et al. Elaboração e análise sensorial de massa de pizza com farinha de amêndoas da castanha de caju. Blucher Chem. Eng. Proc., v.1, n.2, p. 3924-3930, 2015. doi: 10.5151/ chemeng-cobeq2014-0766-24113-182744

PINHO, B.H.S.; MACHADO, M.I.F.; FURLONG, E.B. Propriedades físico-químicas das massas de pizza semiprontas e sua relaçäo com o desenvolvimento de bolores e leveduras. Rev. Inst. Adolfo Lutz, v.60, n.1, p. 35-41, 2001.

QUAGLIA, G. Ciencia y tecnologia de la panificación. Zaragoza: Acríbia, 1991. 
RIOS, M.N.S.; PASTORE, F.J. Plantas da Amazônia: 450 espécies de uso geral. Brasília: UnB, 2011.

RUSSO, C.B. et al. Aceitabilidade sensorial de massa de pizza acrescida de farinhas de trigo integral e de linhaça (Linum usitatissimum L.) entre adolescentes. Rev Inst Adolfo Lutz, v.71, n.3, p.488-94, 2012.

SILVA, D.T.S.; ARAÚJO, R.S.R.M. Desenvolvimento de massa de pizza enriquecida com farinha de feijão-caupi (Vigna unguiculata (L.) Walp.). Teresina: Universidade Federal do Piauí..2015.

SILVA, R.P.; ALMEIDA, A.K.P.; ROCHA, F.A.G. Os riscos em potencial do uso indiscriminado de plantas medicinais. 2010. Disponível em: <http:/connepi.ifal.edu.br/ocs/anais/conteudo/
anais/files/conferences/1/schedConfs/1/papers/676/public/6764948-1-PB.pdf>. Acesso em: 12 maio 2020.

SOUSA, J. R. P. S. et al. Elaboração de massa de pizza com teor de sódio reduzido e enriquecida com farinha de aveia. Rev. Verde Agroecol. Desenvolv. Sustent., v.11, n.2, p.9-13, 2016. doi: 10.18378/rvads.v11i2.4520

VIZZOTTO, M.; PEREIRA, M. C. Alimentação Viva e Sustentável. Hibisco: do uso ornamental ao medicinal. 2010. Disponível em: <http://www.infobibos.com/Artigos/2008_4/ Hibisco/index.htm>. Acesso em: 13 maio 2020. 